Supplement of Hydrol. Earth Syst. Sci., 25, 2513-2541, 2021

https://doi.org/10.5194/hess-25-2513-2021-supplement

(c) Author(s) 2021. CC BY 4.0 License.

(c) (1)

Supplement of

\title{
The spatial extent of hydrological and landscape changes across the mountains and prairies of Canada in the Mackenzie and Nelson River basins based on data from a warm-season time window
}

Paul H. Whitfield et al.

Correspondence to: Paul H. Whitfield (paul.h.whitfield@gmail.com)

The copyright of individual parts of the supplement might differ from the article licence. 
Supplementary Figures

S1 Missingness and station density plots for stations with continuous and seasonal operations.

S2-S13 Examples of stations from streamflow regime 1 to 12.

S14 Example time series for NDVI, NDWI, NDSI and coverage fraction for catchment 05AA008.

S15. Hydrologic change in the 395 stations ordered by WSC StationID.

S16-S21. Maps showing location of stations with Trend Patterns 1 to 6 with details significant trends in 5 day periods for each station in that group.

S22-S24. Spatial distribution of trends in maximum, mean, and minimum NDVI, NDWI, and NDSI. 

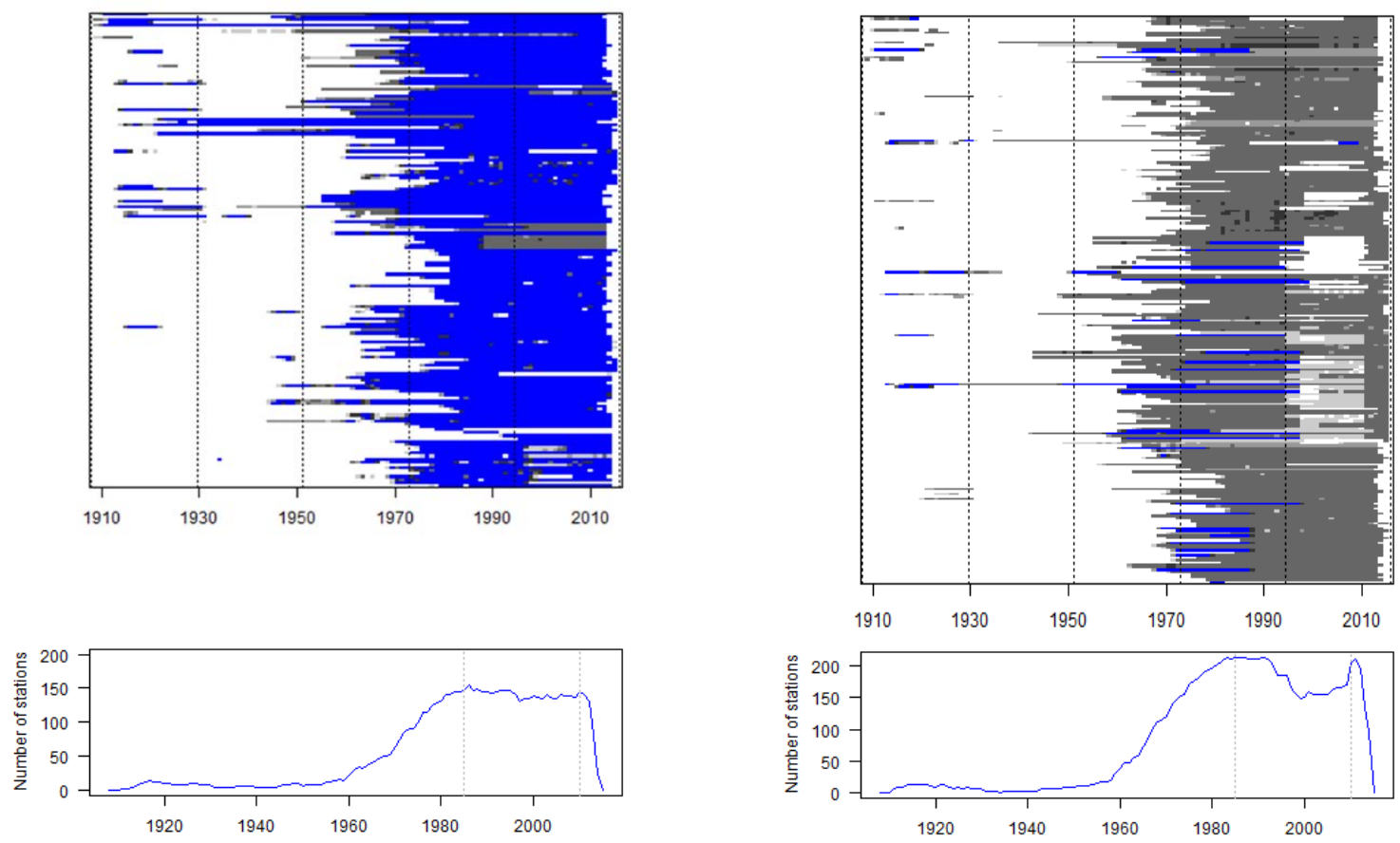

Figure S1. Upper left panel is a missingness plot for the 162 continuous stations, and upper right for the 233 seasonal stations; white indicates no data, and blue indicates complete years and shades of gray partial years. The lower panel indicates the number of available stations in each year, in the most heavily sampled portion, the 25 years from 1985 to 2010 (gray dotted lines) at best only 130 complete years would be available for continuous stations. Using partial years from seasonal stations with more than $50 \%$ data fora year would add up to another 214 stations to some years. The missingness plots show that the data retrieval based upon metadata [active, natural, and 30 years of data] returned data from some stations that could be considered to not meet the desired conditions.

Figure 

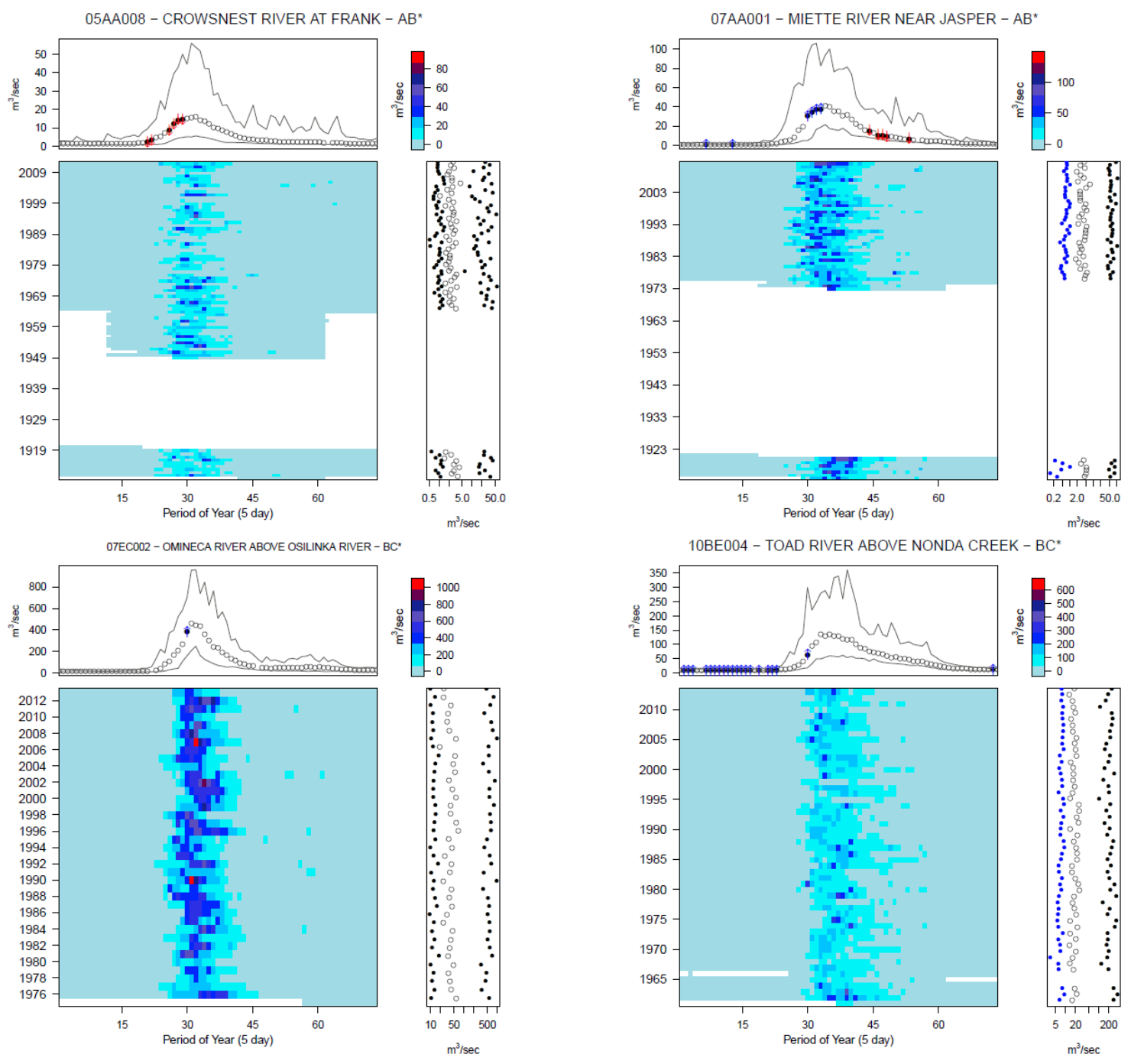

Figure S2. Examples of stations from Streamflow Regime (cluster) $1(n=104)$, predominantly mountain watersheds. Station names appended with * are from the Reference Hydrological Basin Network (RHBN). For each cluster examples were preferentially chosen from among RHBN and different portions of the study area. 

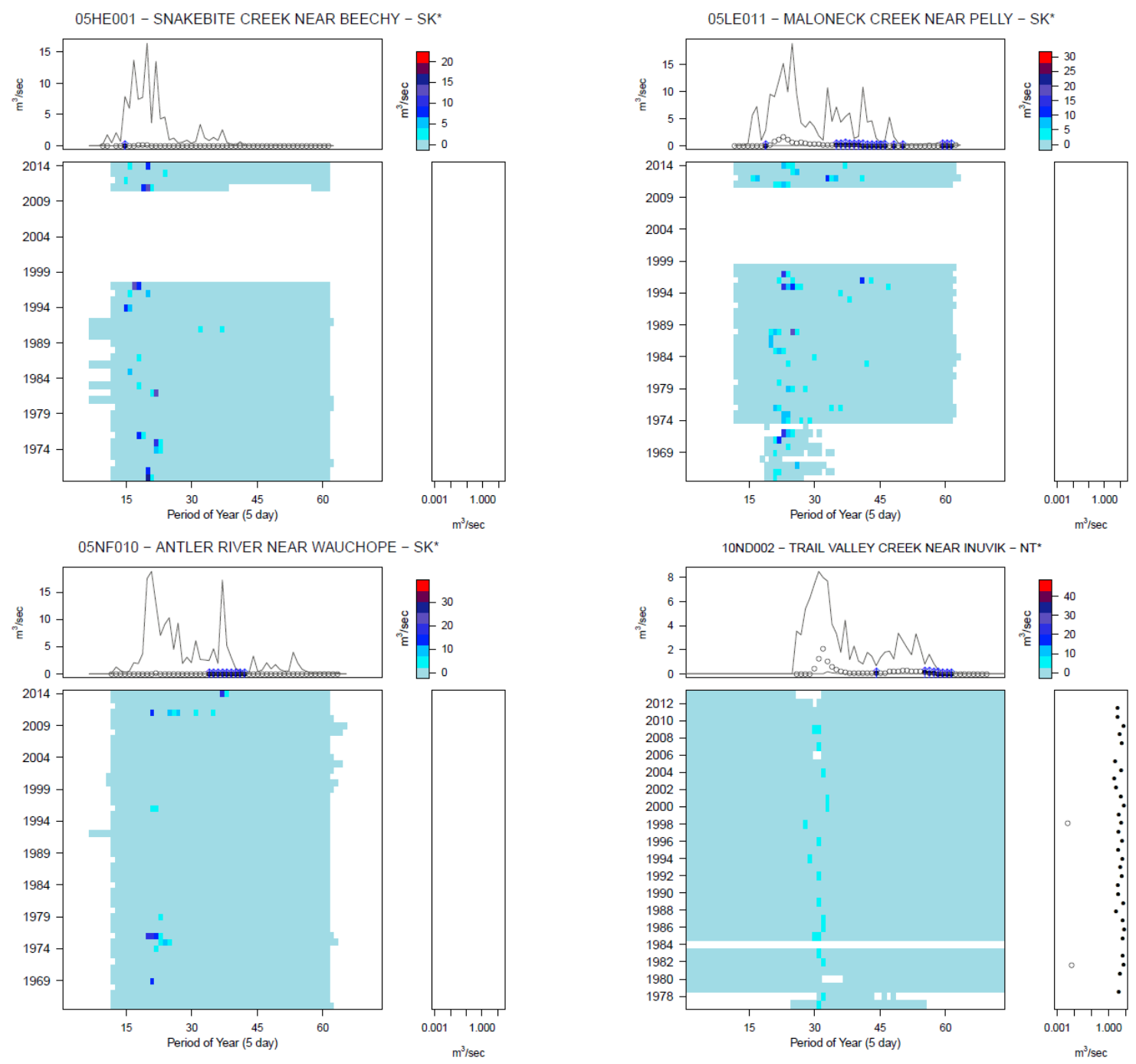

Figure S3. Examples of stations from Streamflow Regime (cluster) $2(n=85)$ predominantly Prairie watersheds. 

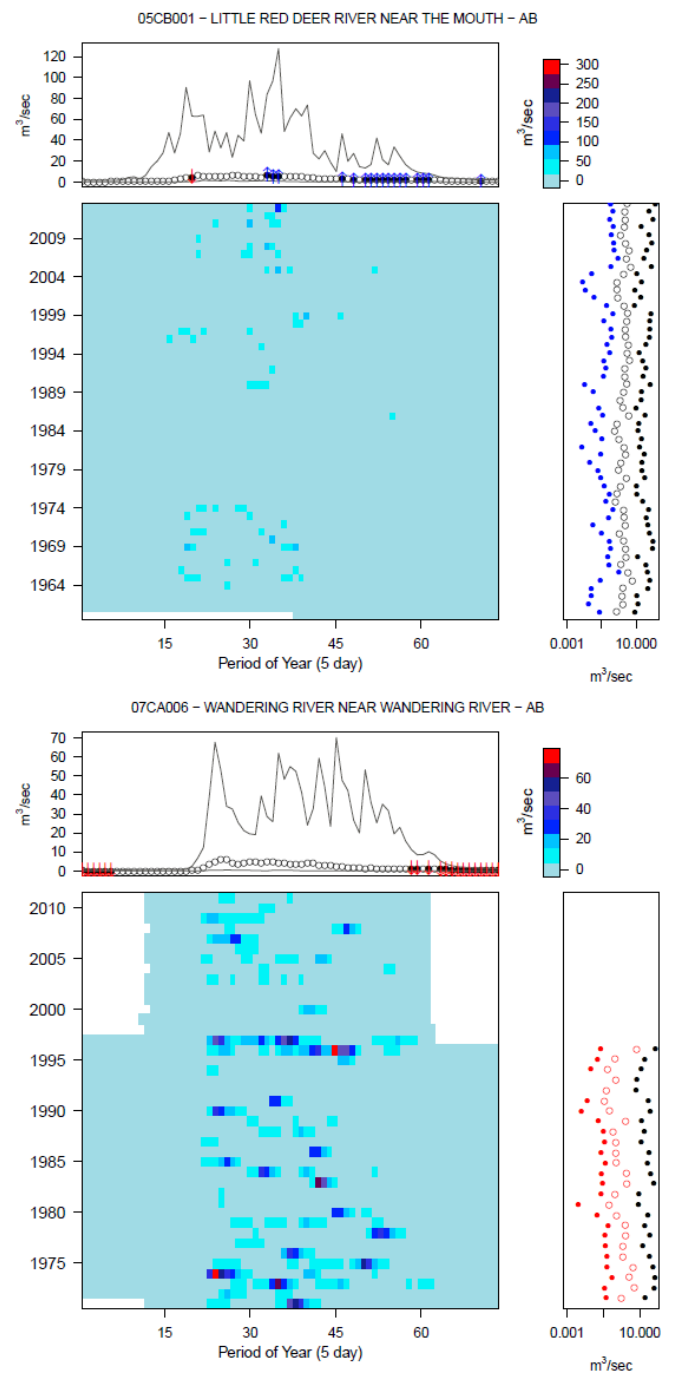
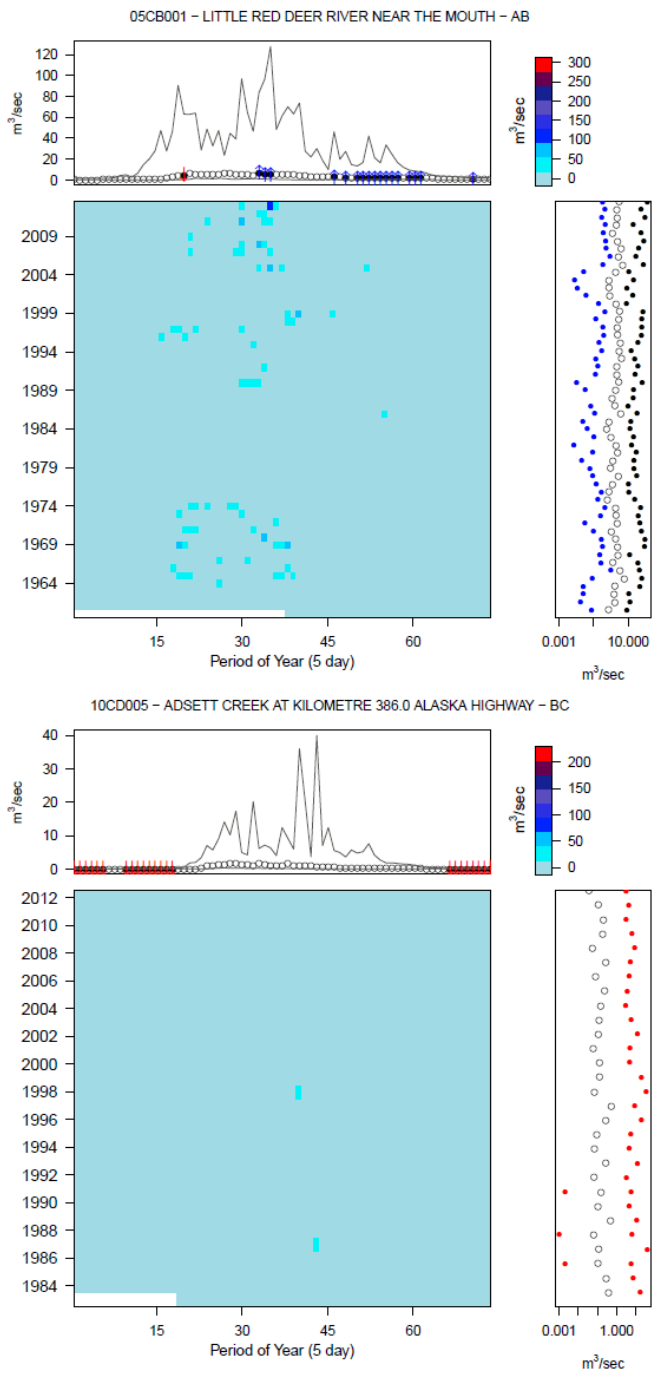

Figure S4. Examples of stations from Streamflow Regime (cluster) $3(n=22)$.primarily along the Athabasca River. 

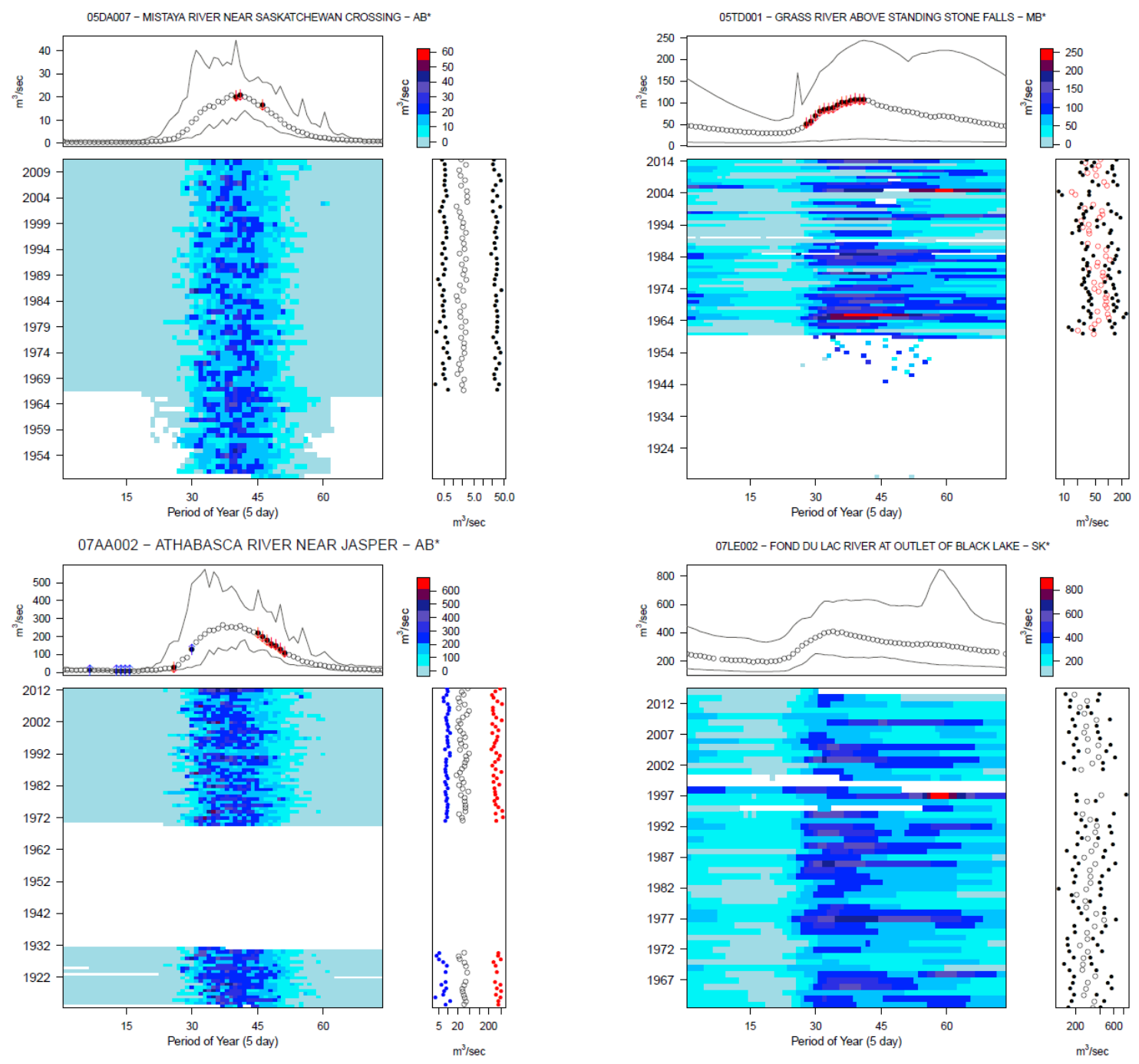

Figure S5. Examples of stations from Streamflow Regime (cluster) 4 ( $n=10)$. 

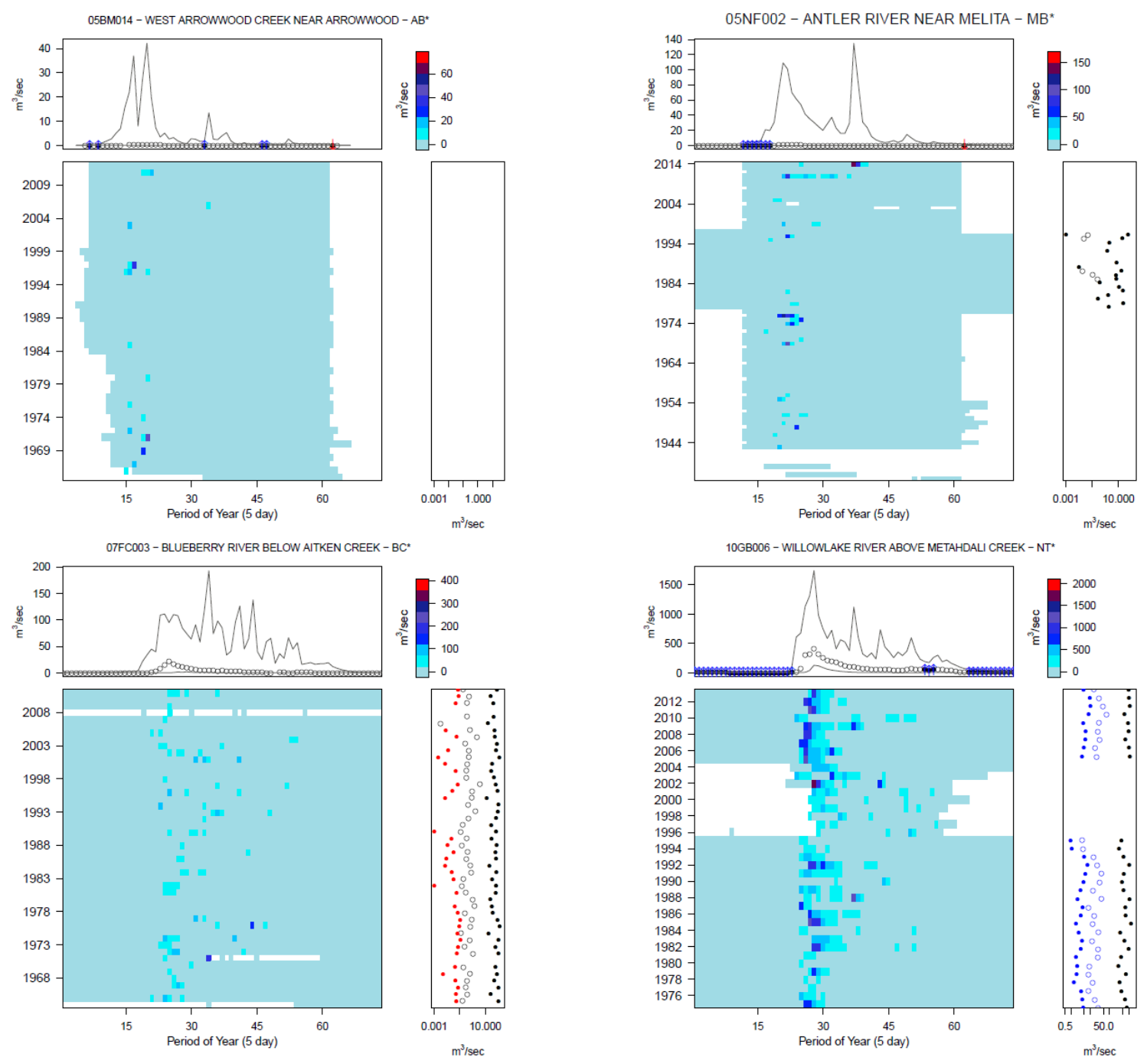

Figure S6. Example of stations from Streamflow Regime (cluster) 5 ( $n=148)$. 


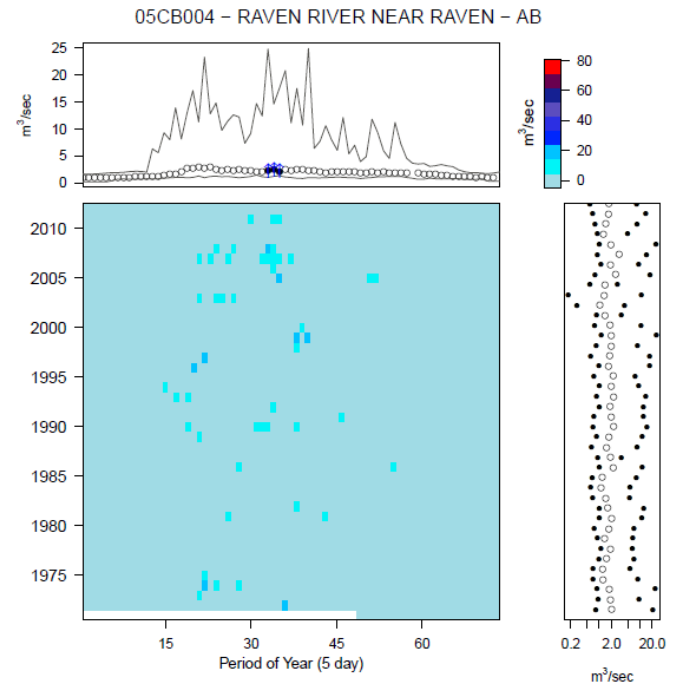

Figure S7. Station from Streamflow Regime (cluster) $6(n=1)$.

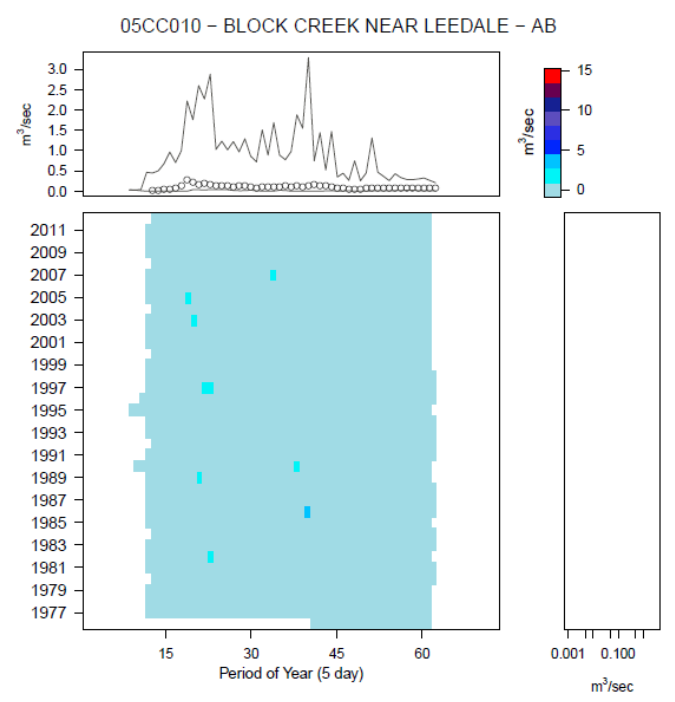

Figure S8. Station from Streamflow Regime (cluster) $7(n=1)$. 


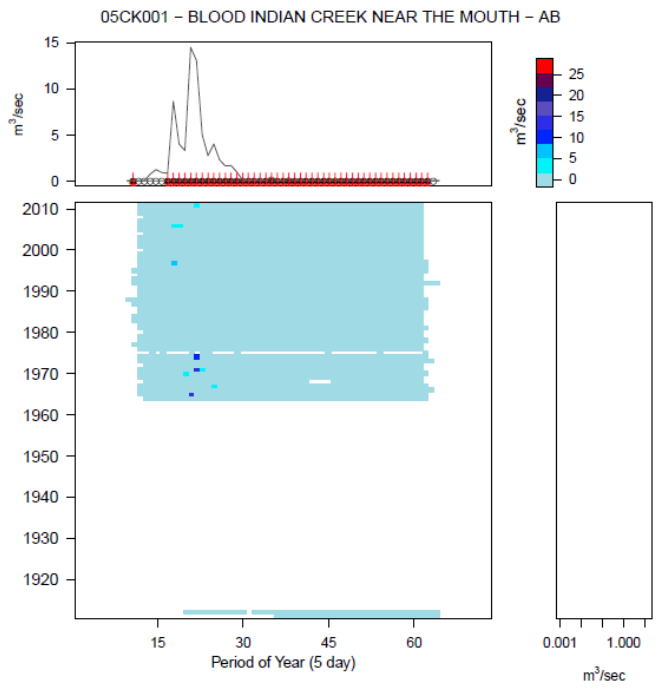

Figure S9. Station from Streamflow Regime (cluster) $8(n=1)$. 

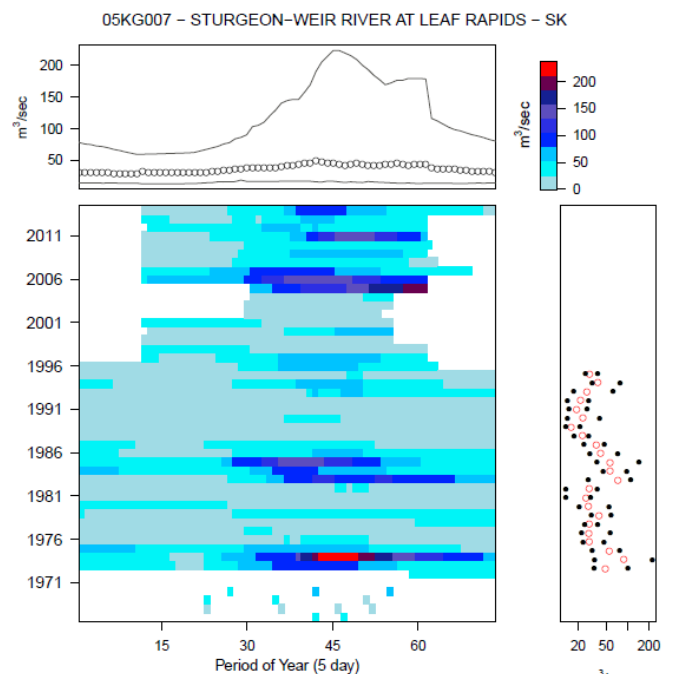

07SA002 - SNARE RIVER BELOW GHOST RIVER - NT
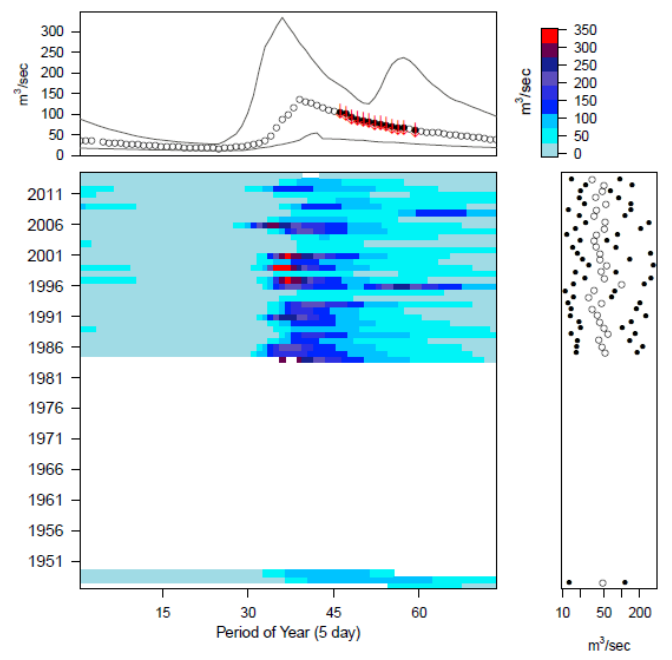

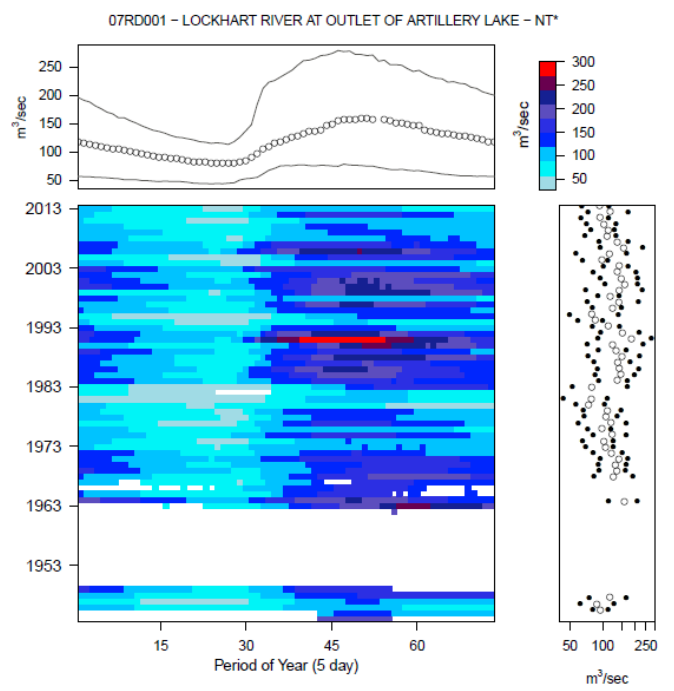

10.JC003 - GREAT BEAR RIVER AT OUTLET OF GREAT BEAR LAKE - NT*
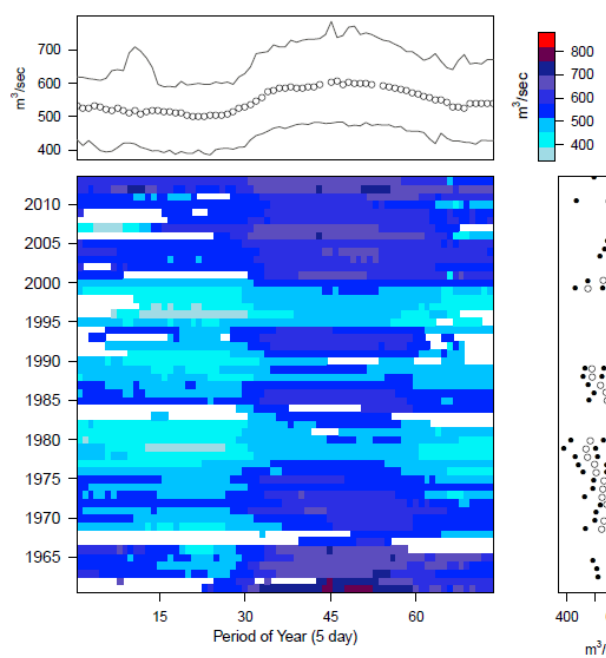

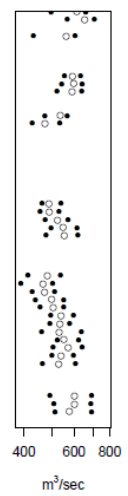

Figure S10. Examples of stations from Streamflow Regime (cluster) $9(n=5)$. 

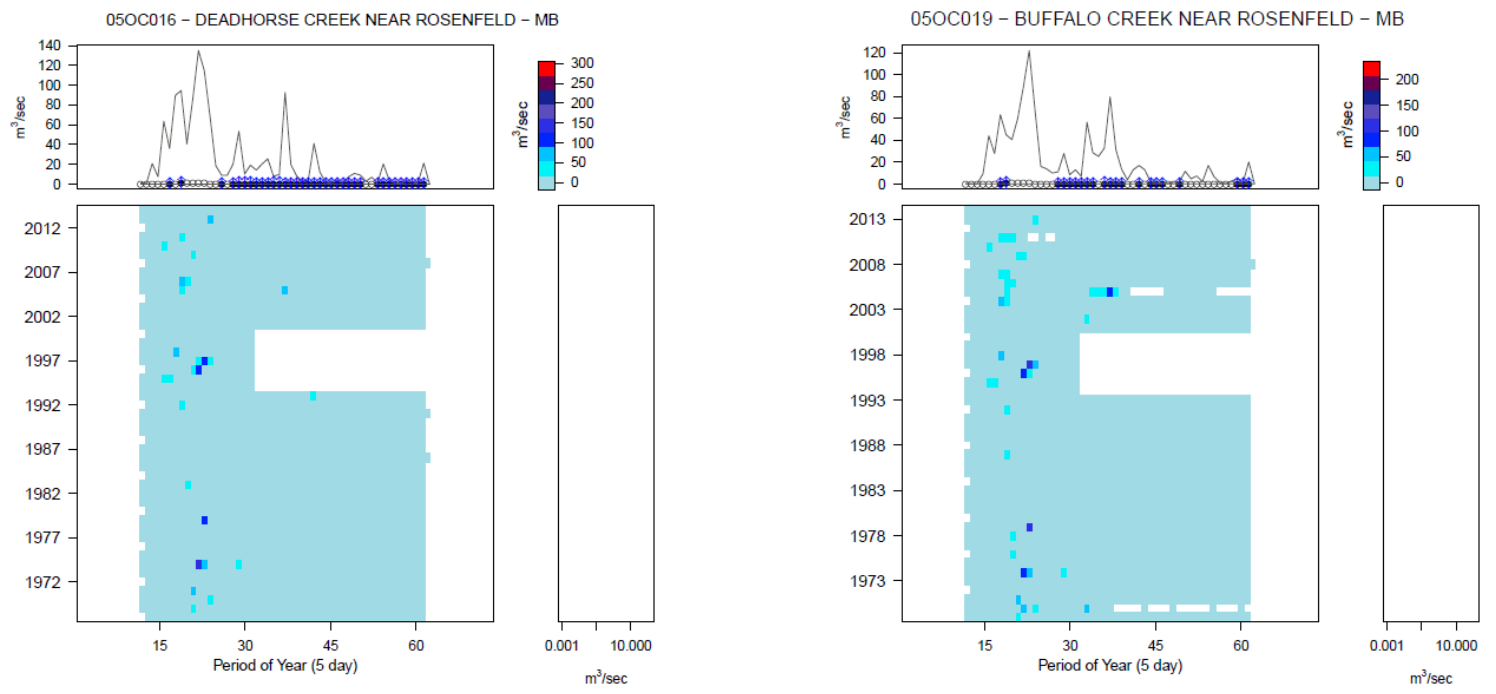

Figure S11. Stations from Streamflow Regime (cluster) 10 ( $n=2)$. 

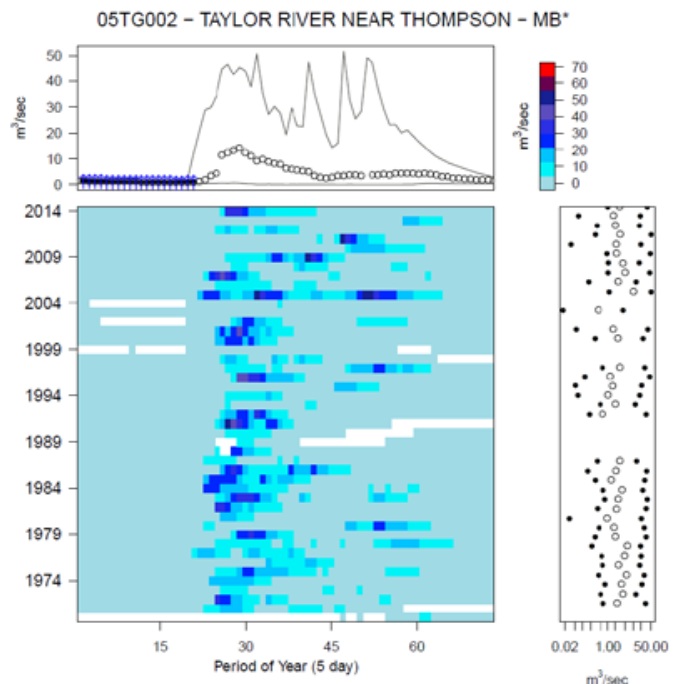

10LA002 - ARCTIC RED RIVER NEAR THE MOUTH - NT*

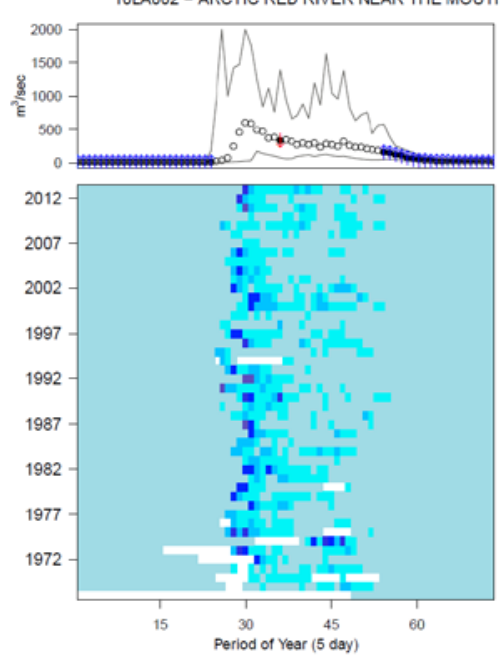

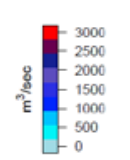

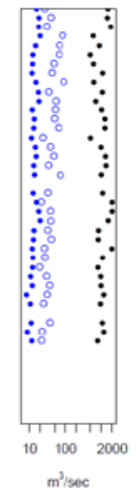

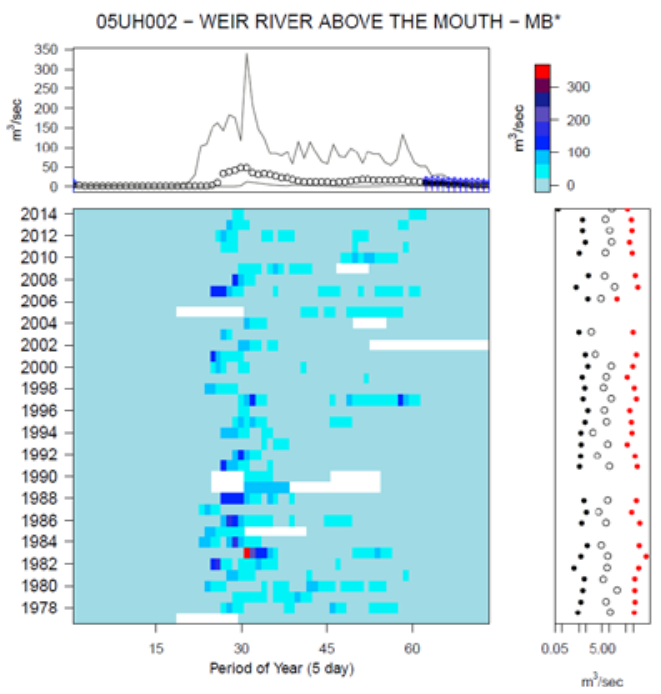

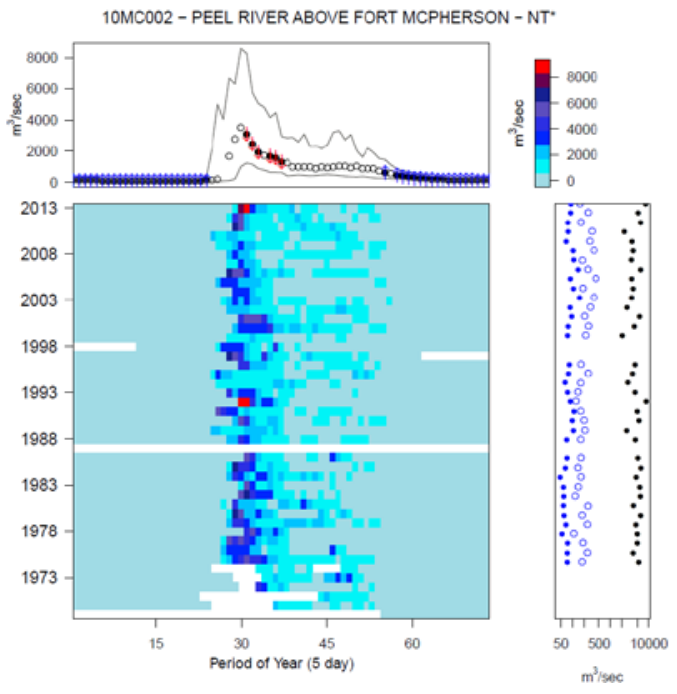

Figure S12. Examples of stations from Streamflow Regime (cluster) 11 ( $n=12)$. 

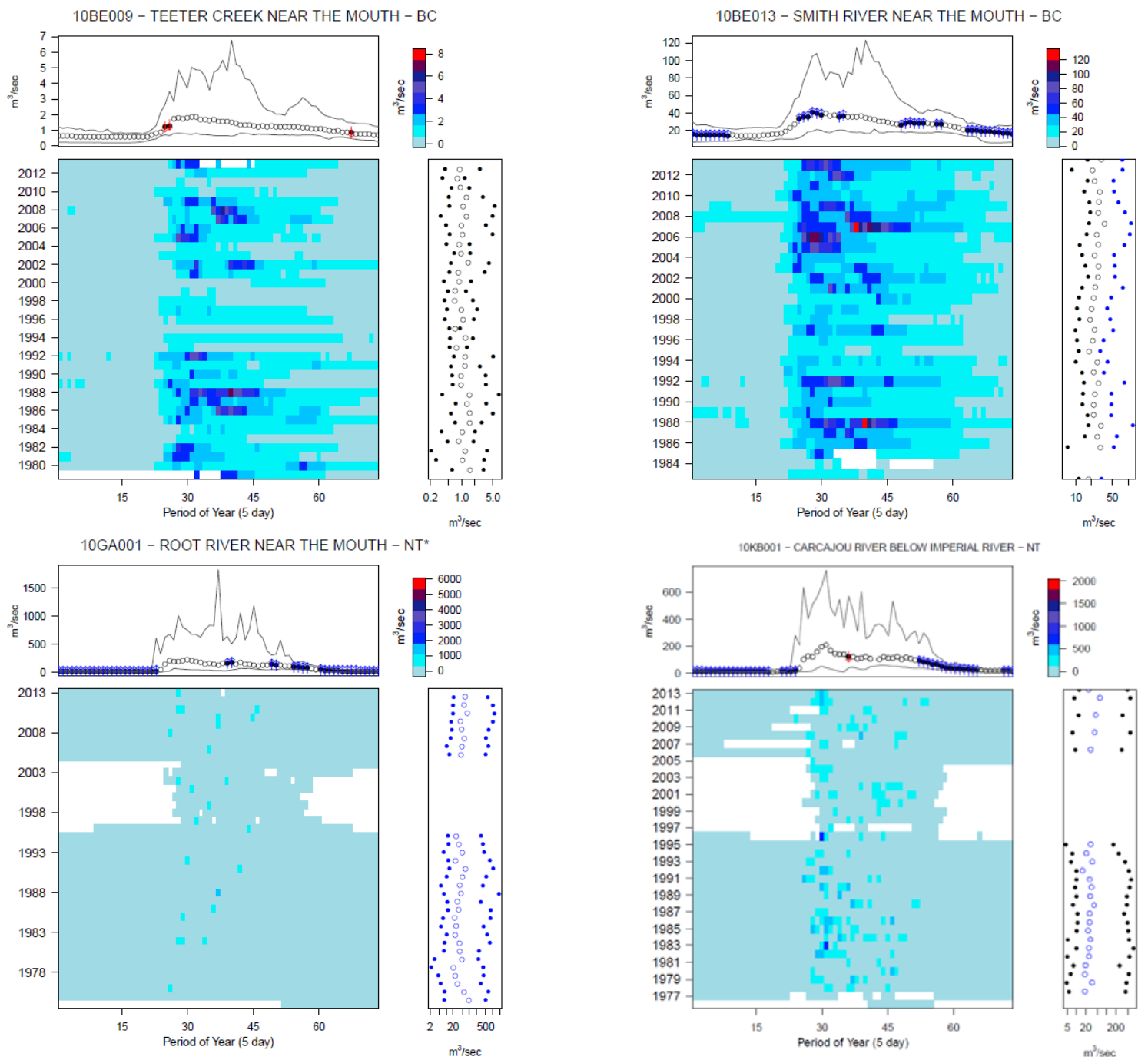

Figure S13. Stations from Streamflow Regime (cluster) $12(n=4)$. 

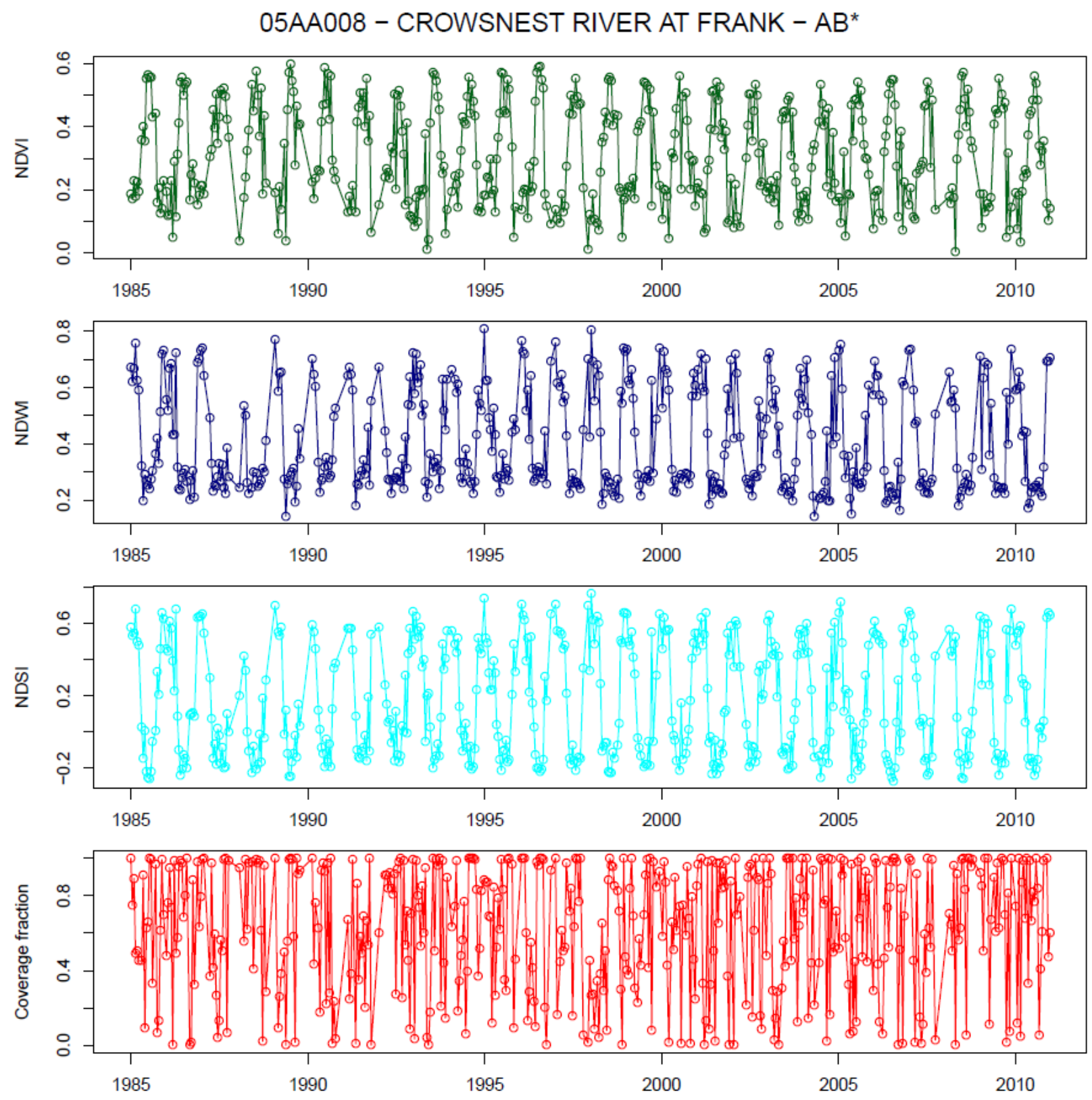

Figure S14. An example of the time series for NDVI, NDWI, NDSI, and Coverage fraction for the catchment 05AA008 Crowsnest River at Frank AB. These values are extracted from Landsat composite images for every sixteen days between 1980 and 2013. 


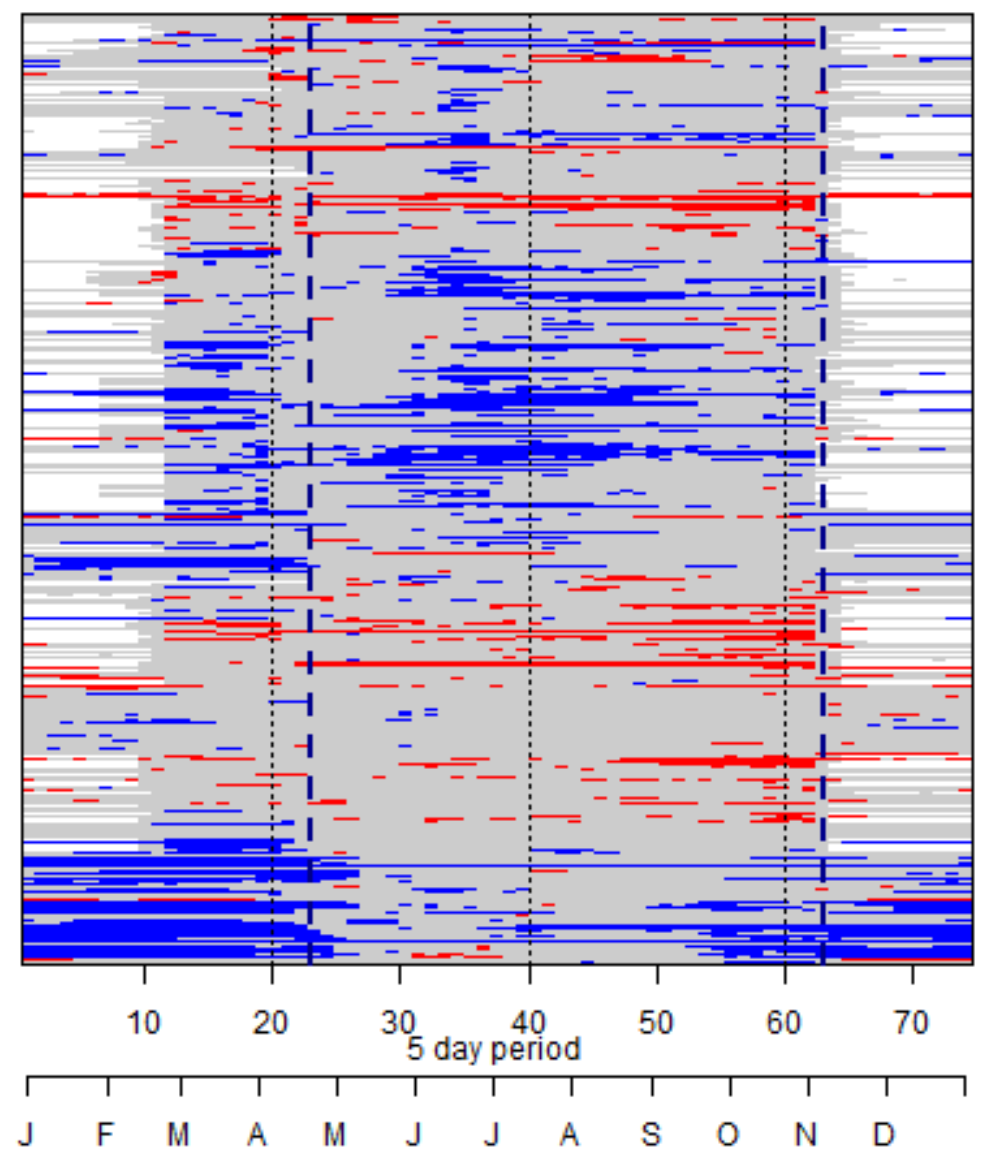

Figure S15. Hydrologic change in the 395 stations across the 73 five day periods showing significant increases (blue) and significant decreases (red), no trend (gray) and missing (white). The stations are ordered by WSC StationID. 


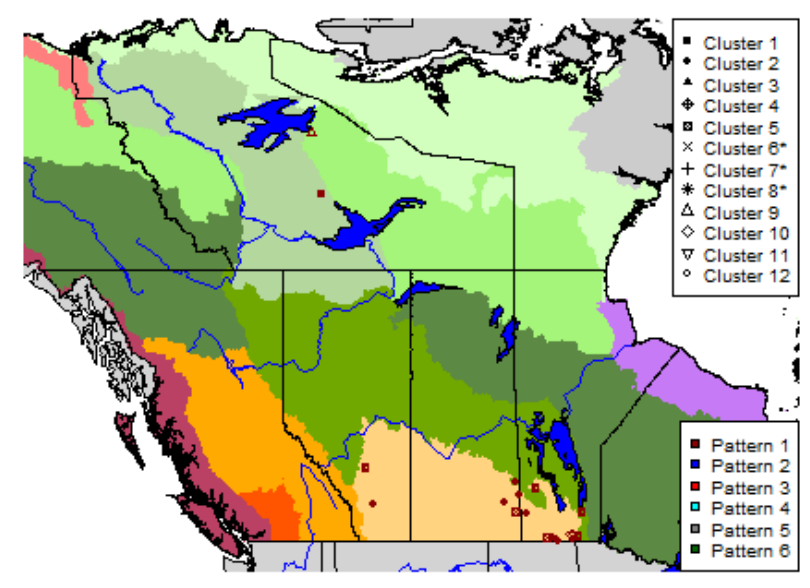

Change Pattern $1 \mathrm{n}=19$

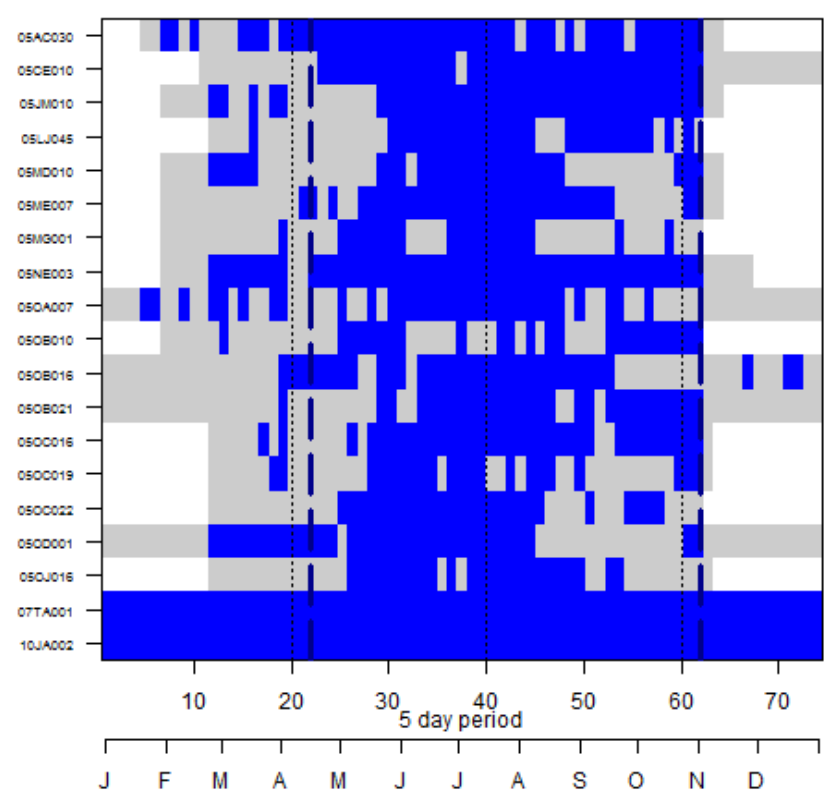

Figure S16. Map (upper) showing location of stations with Trend Pattern 1 (lower; $n=19$ ). Increases in summer and fall streamflow. Significant decreases in red, increases in blue, no trend in gray, and no data in white. Clustering was based upon periods 23 to 61. Periods 1-22 and 62-73 do not have observations in all cases. 


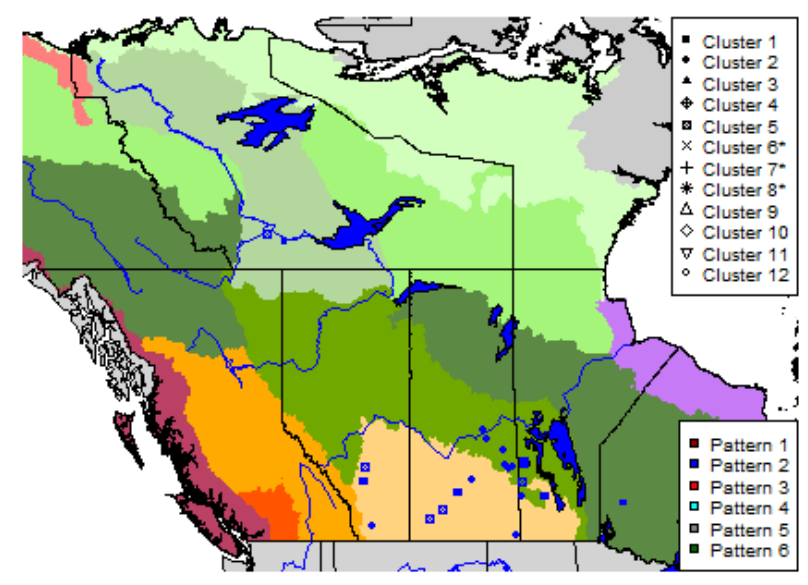

Change Pattern $2 \mathrm{n}=\mathbf{2 2}$

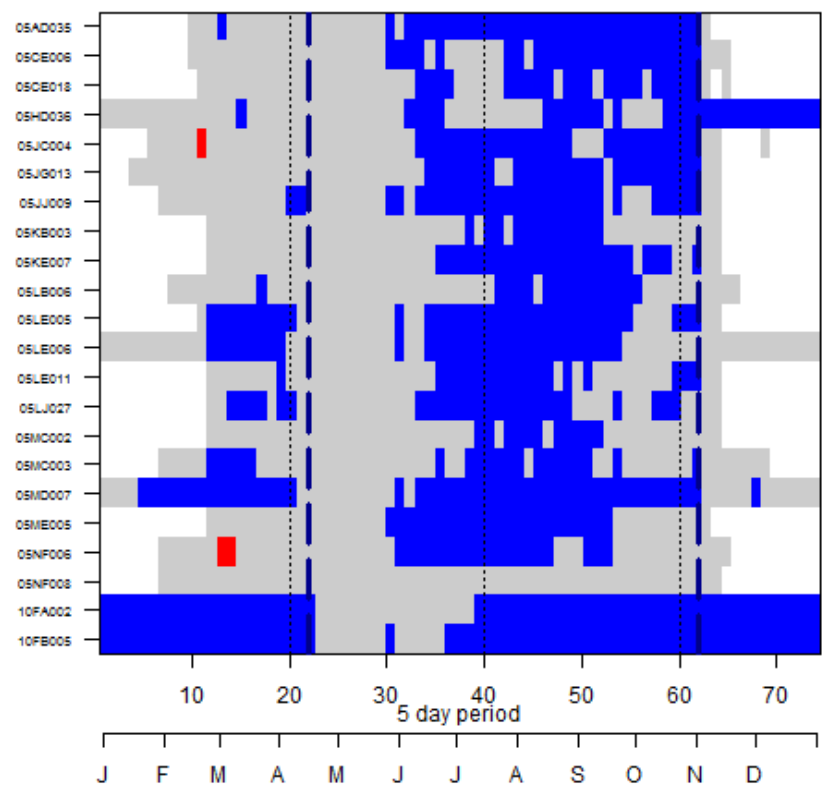

Figure S17. Map (upper) showing location of stations with Trend Pattern 2 (lower; $n=22$ ). Increases in streamflow in late summer and fall but not spring. Significant decreases in red, increases in blue, no trend in gray, and no data in white. Significant decreases in red, increases in blue, no trend in gray, and no data in white. Clustering was based upon periods 23 to 61. Periods 1-22 and 62-73 do not have observations in all cases. 


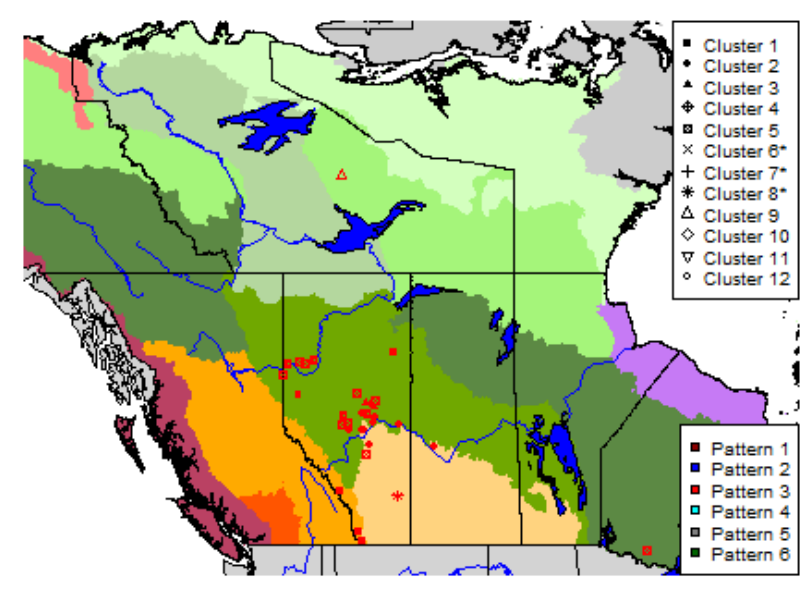

\section{Change Pattern $3 \mathbf{n =} \mathbf{3 2}$}

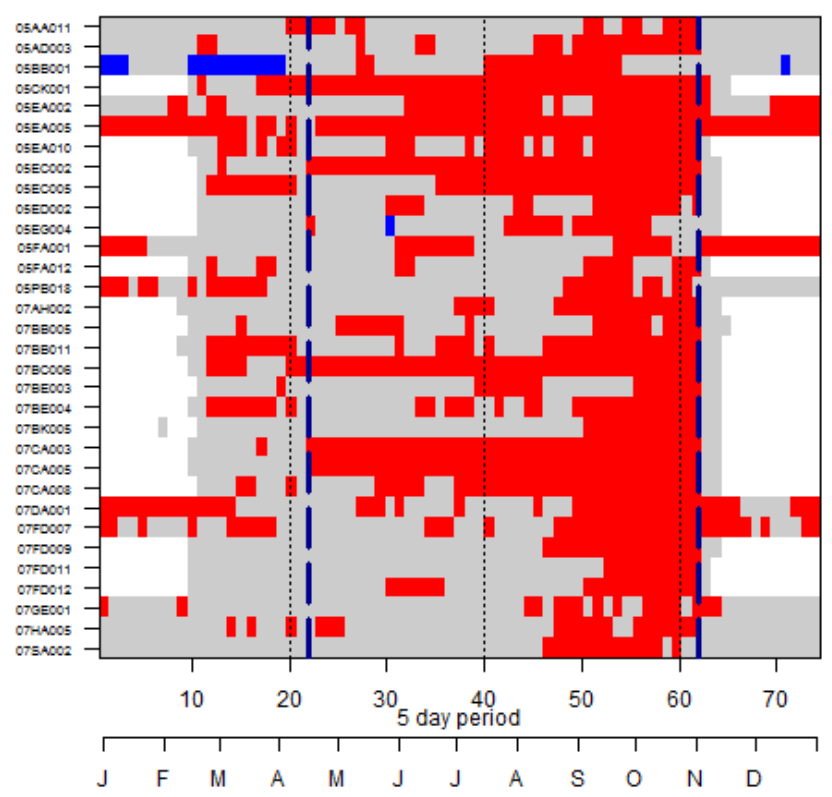

Figure S18. Map (upper) showing location of stations with Trend Pattern 3 (lower; $n=32$ ). Decreases in streamflow, predominately in late summer and fall. Significant decreases in red, increases in blue, no trend in gray, and no data in white. Clustering was based upon periods 23 to 61 . Periods 1-22 and 6273 do not have observations in all cases. 


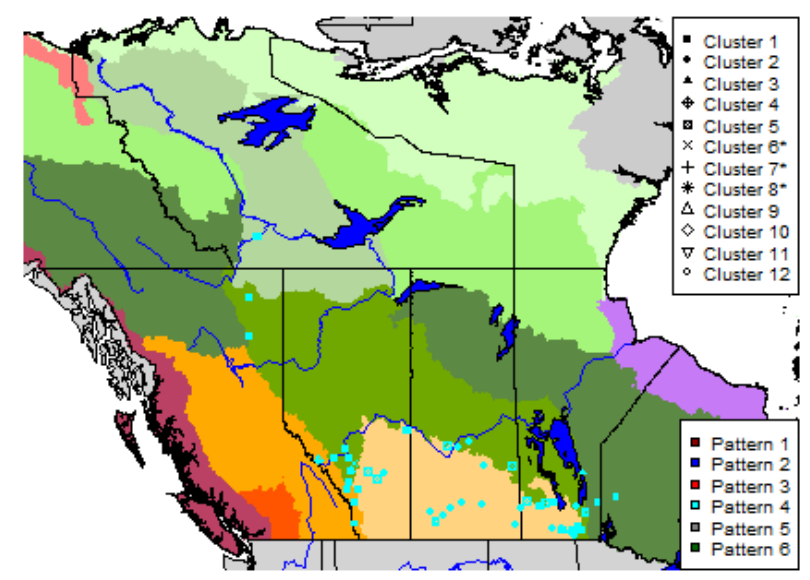

Change Pattern $\mathbf{4} \mathbf{n}=\mathbf{5 0}$

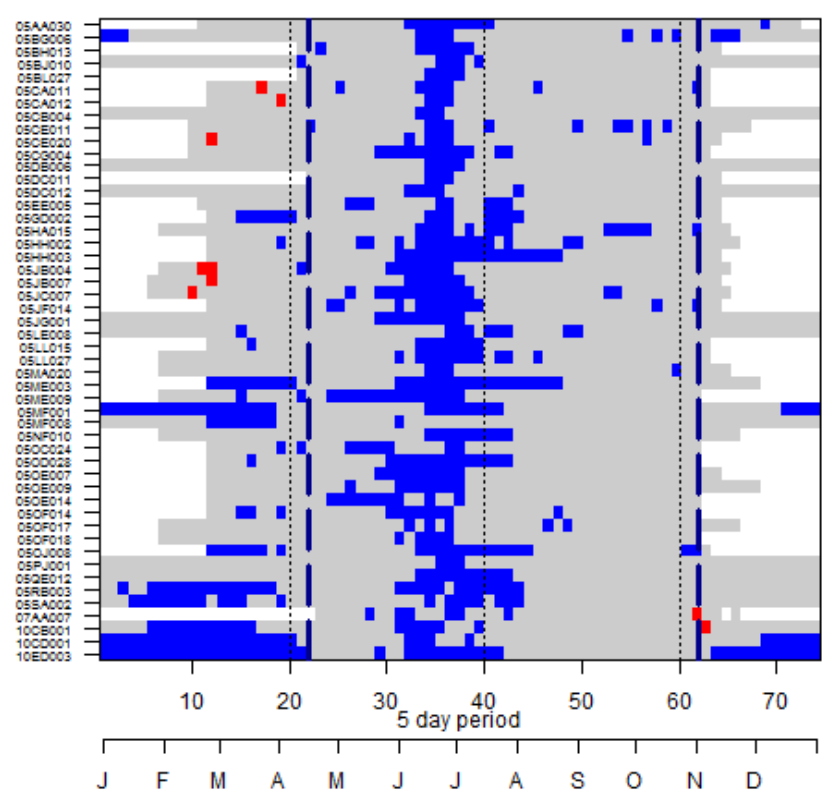

Figure S19. . Map (upper) showing location of stations with Trend Pattern 4 (lower; $n=50$ ). Increases in spring discharge centered on period 33-38, but few changes outside those periods. Significant decreases in red, increases in blue, no trend in gray, and no data in white. Clustering was based upon periods 23 to 61 . Periods 1-22 and 62-73 do not have observations in all cases. 


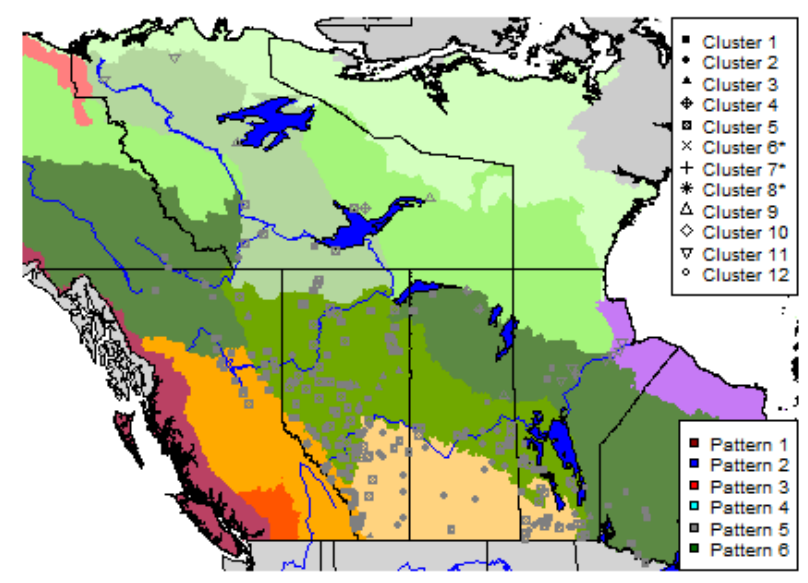

\section{Change Pattern $5 \mathrm{n}=\mathbf{2 5 4}$}

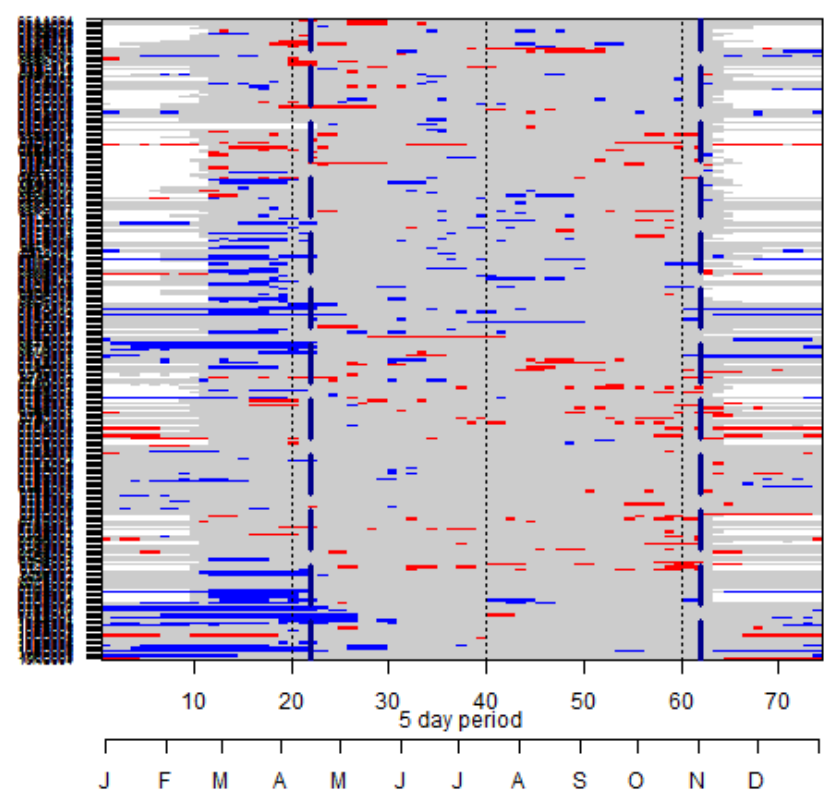

Figure S20. . Map (upper) showing location of stations with Trend Pattern 5 (lower; n=254). No organized pattern of change in the period of the year used to cluster; some increases in winter discharge. Significant decreases in red, increases in blue, no trend in gray, and no data in white. Clustering was based upon periods 23 to 61 . Periods 1-22 and 62-73 do not have observations in all cases. 


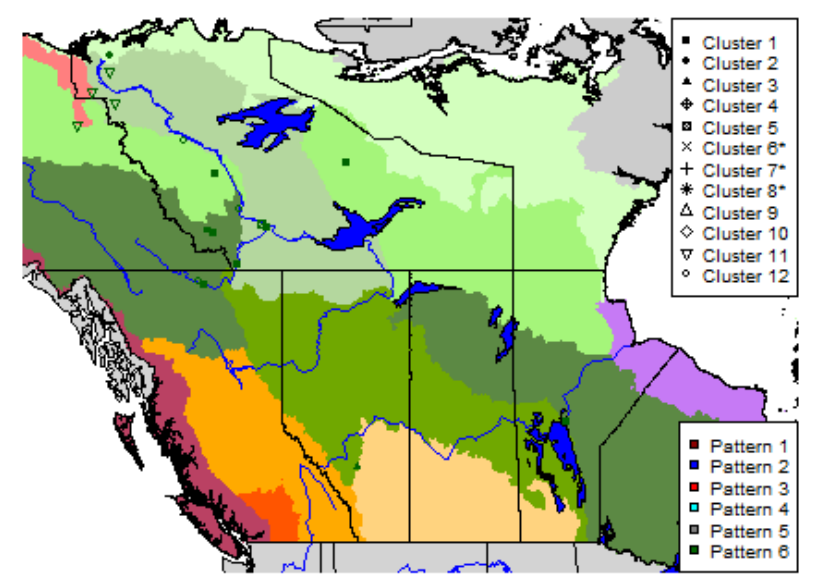

Change Pattern $6 n=18$

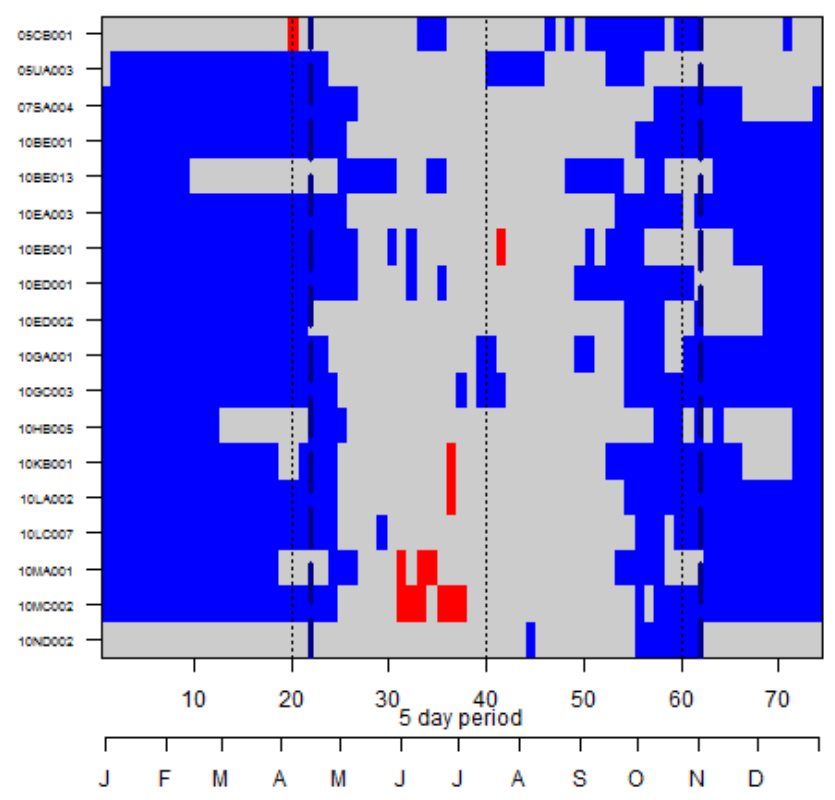

Figure S21. . Map (upper) showing location of stations with Trend Pattern 6 (lower; $n=18$ ). Increases in fall discharge (periods 55-61) but little consistent change in summer and increases in winter discharge. Significant decreases in red, increases in blue, no trend in gray, and no data in white. Clustering was based upon periods 23 to 61 . Periods 1-22 and 62-73 do not have observations in all cases. 

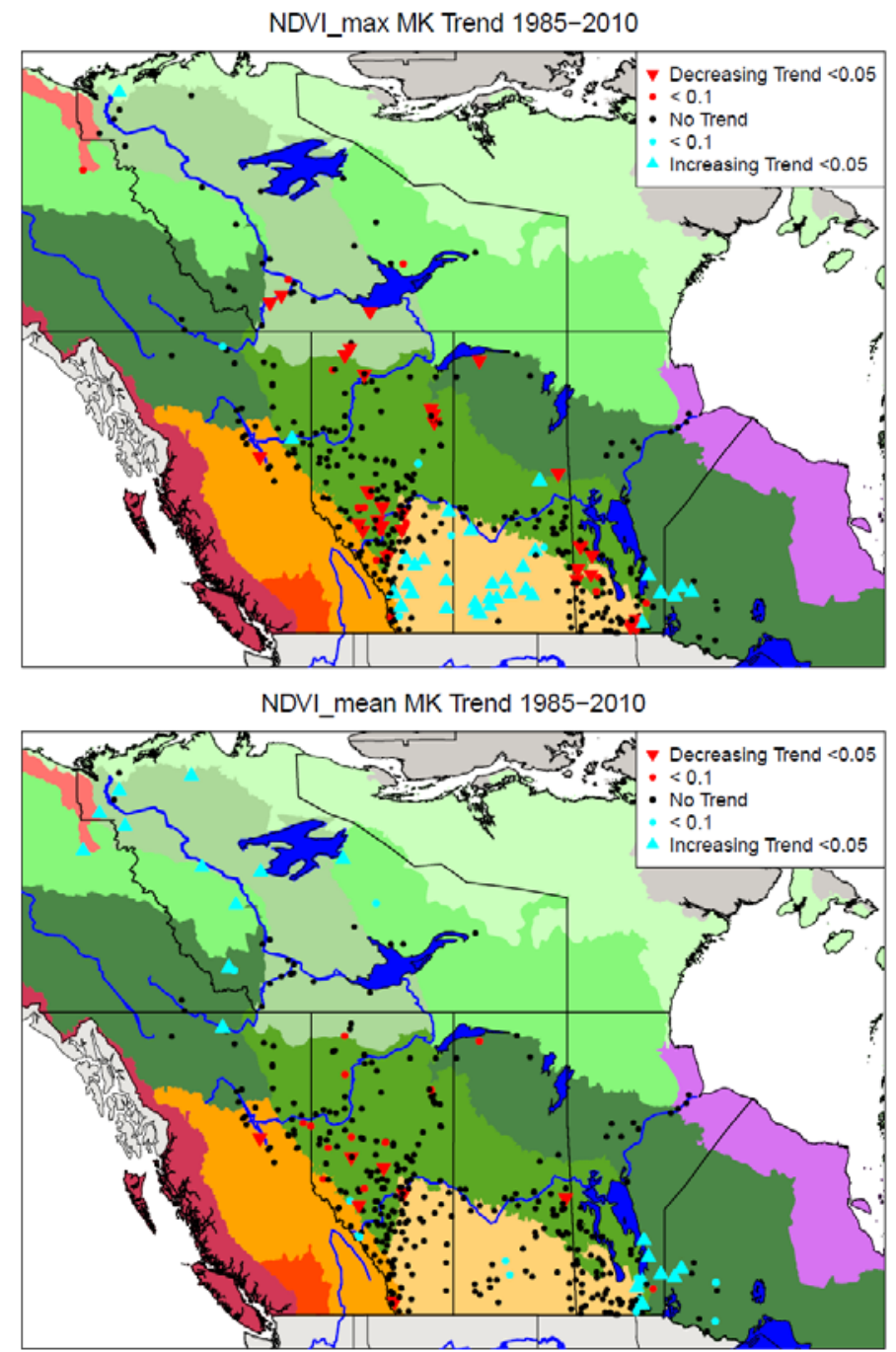

NDVI_min MK Trend 1985-2010

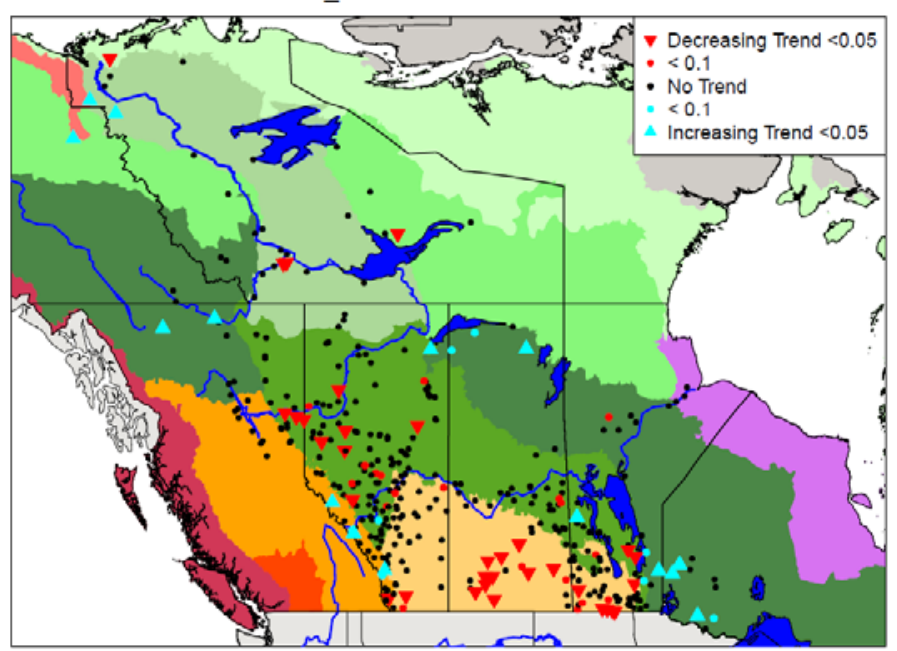

Figure S22. Trends in maximum, mean, and minimum NDVI between 1985 and 2012. 

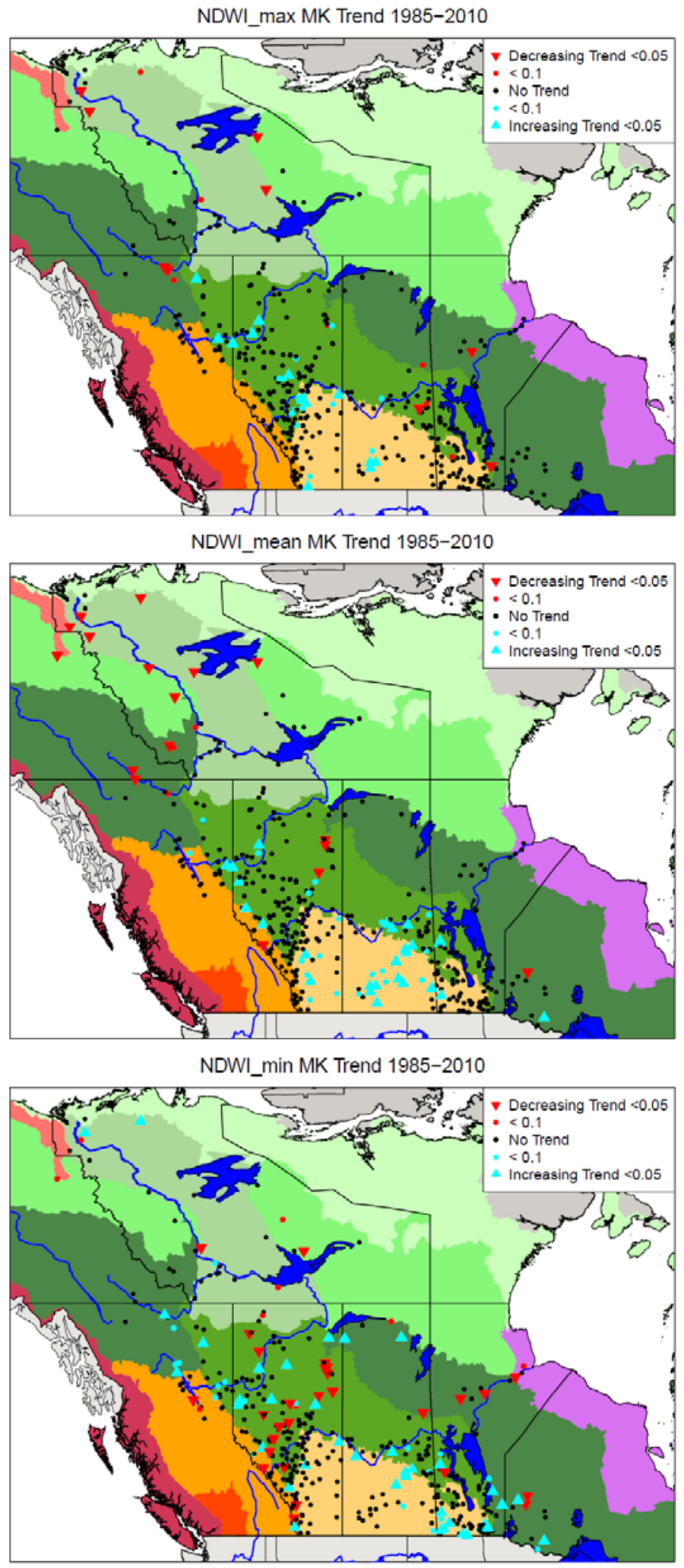

Figure S23. Trends in maximum, mean, and minimum NDWI between 1985 and 2012 

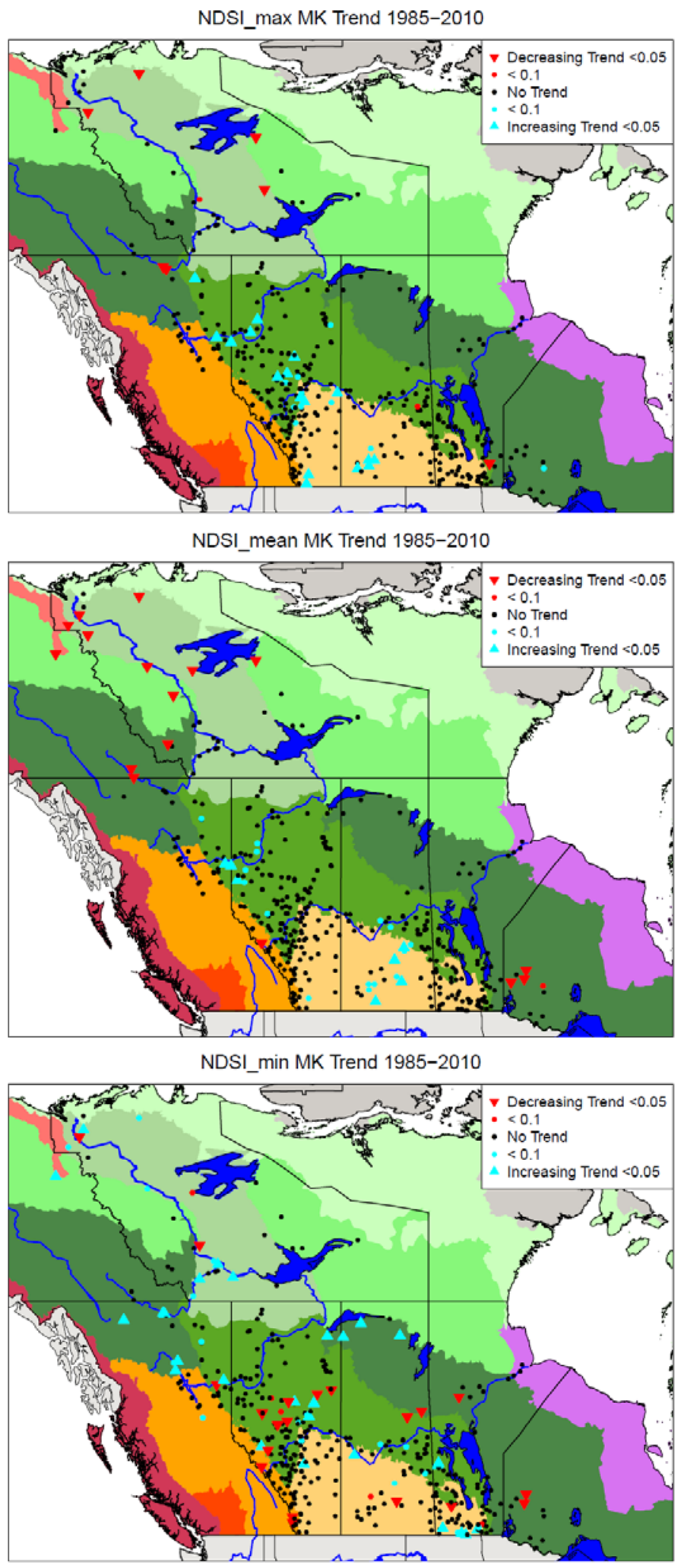

Figure S24. Trends in maximum, mean, and minimum NDSI between 1985 and 2012. 